\title{
Development of consonants and vowels in a child with cri du chat syndrome
}

\author{
KRISTIAN EMIL KRISTOFFERSEN \\ Department of Linguistics, University of Oslo, Norway
}

\begin{abstract}
Language development in persons with cri du chat syndrome (CDCS) has only been described in very general terms. Three tendencies have been noted in the literature: First of all, there is a discrepancy between chronological age and linguistic age in children with CDCS. Second, there is a discrepancy between receptive and expressive linguistic abilities in these children. Third, their articulation is characterized by omissions and substitutions. However, little is known about the exact nature of these articulation problems. In this paper longitudinal phonological data from a Norwegian girl with CDCS are presented and compared to data from normally developing Norwegian-speaking children.
\end{abstract}

Keywords: Cri du chat-syndrome, phonological development, consonants, vowels

\section{Introduction}

CDCS is a rare ( 1 in 50000 births) genetic disorder resulting from loss or displacement of material from the short arm of chromosome 5. Symptoms include high pitched cry (perceptually and acoustically similar to the mewing of kittens), moderate to severe psychomotor and mental retardation, and delayed language development.

Language development in persons with CDCS has only been described in very general (non-linguistic) terms. Three tendencies have been noted in the recent literature (cf. Cornish \& Pigram 1996; Cornish \& Munir 1998; Cornish, Bramble, Munir \& Pigram 1999; Cornish, Cross, Green, Willatt and Bradshaw 1999): First, there is a discrepancy between chronological age and linguistic age in children with CDCS. Second, there is a discrepancy between their receptive and expressive 
linguistic abilities. Third, their articulation is characterized by omissions and substitutions. Unfortunately, no details are given in the literature concerning the mentioned articulation problems.

\section{Method and research question}

The subject of this study was a girl, H, with CDCS. My data represent speech samples elicited from her at three different ages; 4;6, 5;9 and 7;0. The samples were elicited by a picture and object naming test developed on the basis of the tester's knowledge of her active vocabulary. At each stage about 100 words were elicited. The words were transcribed in IPA.

The study aimed at answering the following question: What similarities and differences are there between the development of H's speech and the development of speech in normally developing children?

\section{Target language}

H's target language is Urban East Norwegian (UEN; described by G. Kristoffersen 2000), with the following phoneme inventories word initially, word medially and word finally:

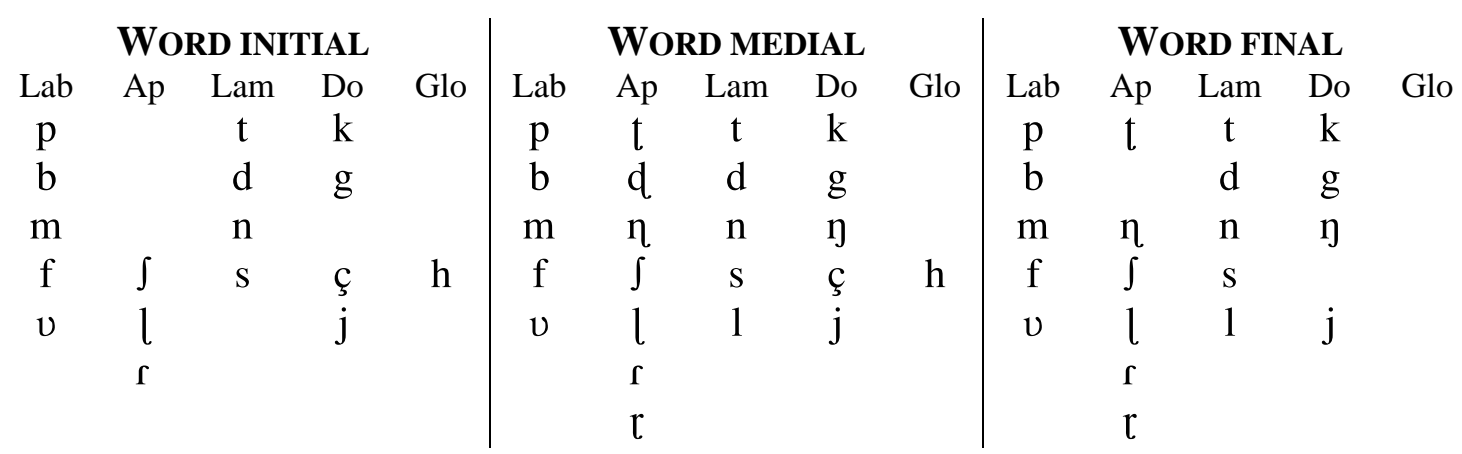

UEN has the following vowel phonemes in stressed syllables; all vowels in (2) can be long or short:

(2) Long: i:, y:, u:, u:, e:, ø:, o:, æ:, á

Short: i, y, u, e, ø, 0, æ, á 
Vowels in unstressed syllables are always short. In addition to the short vowels listed in (2), [ë] appears in unstressed syllables.

\section{Phonetic inventories}

\section{Consonants}

The inventories of H's consonant phones at the three different stages are presented in (3) - (5) (when a phonetic symbol appears within parentheses, the sound it represents occurs only once in the material):

(3) Phonetic inventory at $4 ; 6$

Plosive

NASAL

FRICATIVE

APPROXIMANT

OTHER
LABIAL

$\mathrm{p}$

$\mathrm{m}$

(v)

(4) Phonetic inventory at 5;9

LABIAL

Plosive

NASAL $\mathrm{p},\left(\mathrm{p}^{\mathrm{m}}\right)$

$\mathrm{m}$

FRICATIVE

APPROXIMANT

OTHER

(5) Phonetic inventory at 7;0

LABIAL

Plosive

NASAL

$$
\mathrm{p}
$$

$\mathrm{m}$

FRICATIVE

APPROXIMANT

OTHER

(v)

\begin{abstract}
CORONAL
\end{abstract}
DORSAL

$\mathrm{c}, \mathrm{k}$

$\mathrm{n}, \mathrm{y}$

n $\mathrm{n}, \mathrm{n}$

1,1

$\mathrm{j}$

h

$?$

GLOTTAL

GLOTtAL

$\mathrm{t}, \mathrm{t},\left(\mathrm{t}^{\mathrm{n}}\right) \quad \mathrm{c}, \mathrm{k}$

$\mathrm{n}$

n, $\mathrm{\eta}$

h

j

?

GLOTTAL

$\mathrm{c}, \mathrm{k},\left(\mathrm{k}^{\mathrm{p}}\right)$

j, $\mathrm{y}$

$\mathrm{n}$

$\theta$ h

$?$

The active articulator involved in the production of the lateral approximant varies at all three stages: /// stands for either an apical or a laminal phone. The allophonic variation between palatal and velar dorsals, which is also found in the target language, is dependent on the following and in case of the nasal also the preceding tautosyllabic 
sound - the velar allophone is triggered by a back vowel, the palatal allophone by all other sounds.

I would like to comment on three features of the inventories in (3) - (5). Firstly, there are no voiced plosives. Secondly, a coronal plosive is absent at 4;6, but appears at $5 ; 9$ and $7 ; 0$. When it appears it varies with respect to the passive articulator, which can be either alveolar/dental or labial. Note that the coronal nasal and approximant do not exhibit a similar pattern of variation. Thirdly, there are examples in the material of plosives with nasal release, two at $5 ; 9$ and one at 7;0.

In this context one obvious question arises: Why does $\mathrm{H}$ have so few consonants, compared to the consonant inventory of the target language? In a discussion of articulation problems in children with CDCS, Cornish, Bramble, Munir and Pigram (1999: 265) point to three possible answers to this question: 1) significant intellectual delay; 2) structural or functional abnormality of the larynx; and 3) hypotonia. Consider first the absence of voiced plosives. This may of course be the result of a significant intellectual delay. However, $\mathrm{H}$ has no problem understanding the differences in meaning which are signaled by this distinction in Norwegian.

Can the absence of voiced plosives instead be the result of a functional or structural abnormality of the larynx? H's inventories at all three stages clearly demonstrate that she does make a distinction between voiced and voiceless consonants, as she has both voiced nasals and voiceless plosives. Thus, as far as the distinction between voiced and voiceless speech sounds in general is concerned, the larynx does its job properly.

The third possibility is that the absence of these consonants is in some way related to the muscular problems associated with CDCS. To be able to produce voiced plosives, there must be a higher air pressure below than above the glottis (cf. Rothenberg 1968; Kent and Moll 1969, Moen, Simonsen, Huseby and Grue 2001). To achieve this it is necessary to enlarge the oral cavity in some way or another. Such an activity demands muscular movement and control, which is a problem for children with CDCS. Thus, the absence of voiced plosives may well be the result of hypotonia. The plosives with nasal release also support such a hypothesis. Furthermore, from my observations of a larger group of persons with CDCS it is clear that many of them have quite severe swallowing problems, which can also be attributed to hypotonia. 
Also the lack of fricatives and / $\mathrm{r}$ / in H's speech is possibly the result of muscular problems. In sum, it is a reasonable hypothesis that the small size of H's consonant inventories to a large extent is the result of hypotonia.

\section{Vowels}

As seen from the inventories in (3) - (5) H's consonants varies a great deal. Her vowels vary even more, and in less systematic ways. The following sketch indicates both the extent of variation and of the few more regular aspects of her vowel articulations.

At all three stages H's vowels appeared to cluster in a few areas in the vowel quadrilateral. At 4;6 she had two close vowels, one unrounded front and one rounded central to back vowel. The front vowel, represented by /i/ in the vowel chart in (6), is quite stable, in the the sense that it does not vary as much as the back vowel, represented by $/ \mathrm{u} /$.

Furthermore, she had three mid vowels, one rounded, front to central (represented by / $/$ /), one central unrounded represented by /ə/), and one back rounded, represented by /o/. Finally, she had one unrounded mid to open vowel, represented by /a/. This situation i summarized in (6):

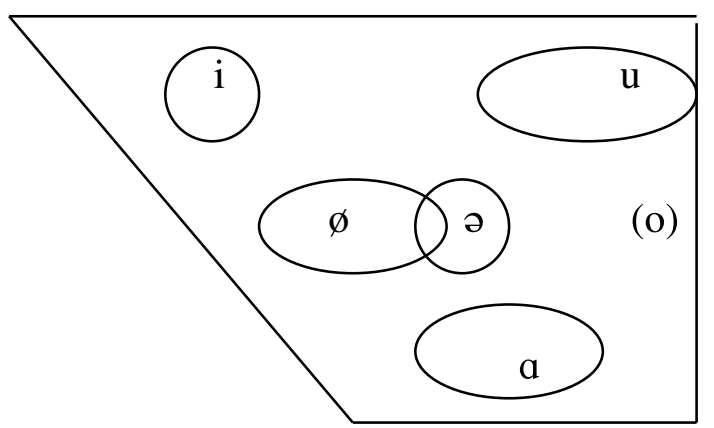

Turning to $5 ; 9$ there is one clear difference from the pattern $\mathrm{H}$ had at 4;6: the rounded mid back vowel has become more frequent at this stage. At 5;9 $\mathrm{H}$ also had an unrounded front mid vowel /e, which does not display much variation/. The vowels at $5 ; 9$ are illustrated in (7): 
(7)

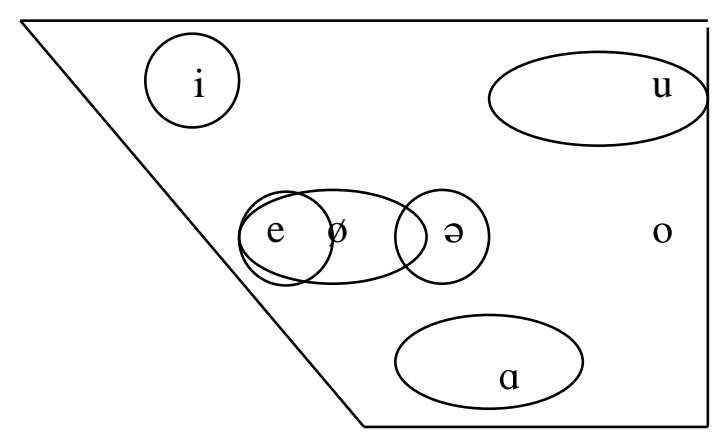

From 5;9 to 7;0 there are no further changes in H's vowel productions. Thus, (7) also illustrates her vowels at that age.

The target vowels that are clearly missing from her system, however, are /y/ and // - vowels that are also known to be acquired last in normally developing children (cf. Simonsen 1990). In sum, it is clear that also her vowel inventories are restricted compared to the target language. In addition, her vowel productions are extremely variable.

\section{Contrastive consonant phones}

Next, consider the development of contrastive consonant phones in H's speech in word initial, word medial and word final position:

(8) Contrastive phones at 4;6

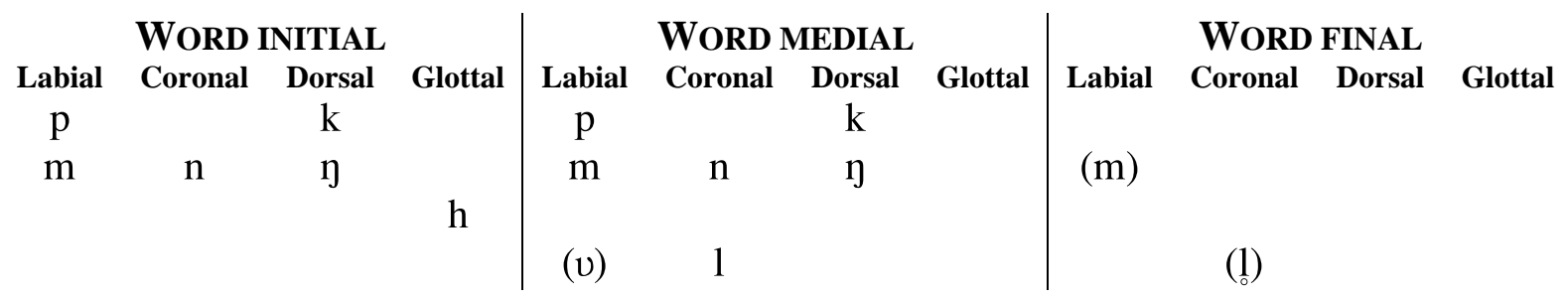

(9) Contrastive phones at 5;9

\begin{tabular}{|c|c|c|c|c|c|c|c|c|c|c|c|}
\hline \multicolumn{4}{|c|}{ WORD INITIAL } & \multicolumn{4}{|c|}{ WORD MEDIAL } & \multicolumn{4}{|c|}{ WORD FINAL } \\
\hline $\begin{array}{c}\text { Labial } \\
\text { p }\end{array}$ & Coronal & $\begin{array}{c}\text { Dorsal } \\
k\end{array}$ & Glottal & $\begin{array}{c}\text { Labial } \\
\text { p }\end{array}$ & $\begin{array}{c}\text { Coronal } \\
\mathrm{t}\end{array}$ & $\begin{array}{c}\text { Dorsal } \\
k\end{array}$ & Glottal & Labial & $\begin{array}{c}\text { Coronal } \\
t\end{array}$ & $\begin{array}{c}\text { Dorsal } \\
k\end{array}$ & Glottal \\
\hline $\mathrm{m}$ & $\mathrm{n}$ & $(\mathrm{y})$ & & $\mathrm{m}$ & $\mathrm{n}$ & $\eta$ & & $\mathrm{m}$ & $\mathrm{n}$ & $\eta$ & \\
\hline & & $\mathrm{j}$ & $?$ & & 1 & & & & 1 & $\mathrm{j}$ & $?$ \\
\hline
\end{tabular}


(10) Contrastive phones at 7;0

\begin{tabular}{cccc|cccc|cccc}
\multicolumn{4}{c|}{ WORD INITIAL } & \multicolumn{5}{|c|}{ WORD MEDIAL } & \multicolumn{4}{c}{ WORD FINAL } \\
Labial & Coronal & Dorsal & Glottal & Labial & Coronal & Dorsal & Glottal & Labial & Coronal & Dorsal & Glottal \\
$\mathrm{p}$ & & $\mathrm{k}$ & & $\mathrm{p}$ & $\mathrm{t}$ & $\mathrm{k}$ & & $\mathrm{p})$ & $\mathrm{t}$ & $\mathrm{k}$ & \\
$\mathrm{m}$ & $\mathrm{n}$ & & & $\mathrm{m}$ & $\mathrm{n}$ & $\mathrm{n}$ & & & $\mathrm{n}$ & $\mathrm{j}$ & \\
& & & $\mathrm{h}$ & & $\theta$ & & & & $\theta$ & & \\
& $\mathrm{l}$ & $\mathrm{j}$ & & & 1 & & & & 1 & $\mathrm{j}$ &
\end{tabular}

When looked at from this perspective we see that H's phonology develops in several respects. Consider first the set of consonants in word initial position. Here the dorsal nasal disappears between $4 ; 6$ and 7;0. This is in agreement with the phonotactic rules of the target language, where $/ \mathrm{y} /$ can only appear in word medial and word final position. At the same time, $\mathrm{H}$ gradually expands the set of consonants in this position: She adds $/ \mathrm{j}, \mathrm{R} /$ at $5 ; 9$ and $/ 1 /$ at $7 ; 0$.

In medial position the most spectacular developments are the appearance of / $t$ / at $5 ; 9$ and $/ \theta /$ at $7 ; 0$.

In the final system there are hardly any consonants at $4 ; 6$, only one occurence each of $/ 1 /$ and $/ \mathrm{m} /$. However, from this stage to the next she makes a big leap: At 5;9 the set of word final consonants is almost as big as the initial and medial sets. This is a course of development also followed by normally developing children.

\section{Comparison with normal development}

Simonsen (1997: 36 f.) reports from a study of the phonology of two normally developing Norwegian-speaking children (Tomas, 2;0 - 4;1 and Nora, 2;3 - 3;5) that they had problems with the following categories: 1) fricatives (lingual fricatives in general) and all fricatives word finally; 2) /r/; 3) labial sounds in final position; and 4) phonation.

If we compare this with H's phonological development we see certain similarities. First, only one fricative appears during the period studied. Second, she has no /r/. Third, the labials are more restricted in final position than in other positions. In word initial and medial position she has both $/ \mathrm{p} /$ and $/ \mathrm{m} /$ at all three stages. In final position she has one occurence of $/ \mathrm{m} /$ but no $/ \mathrm{p} /$ at $4 ; 6 ; / \mathrm{m} /$ only at $5 ; 9$, and one occurence of $/ \mathrm{p} /$ in addition to $/ \mathrm{m} /$ at 7;0. And fourthly, the distinction 
between voiced and voiceless sounds holds between nasals and plosives, but there is no distinction between voiced and unvoiced plosives.

\section{Summary and conclusion}

In this paper I have presented results from a longitudinal study of the phonological development of a girl with cri du chat-syndrome, with particular focus on the following question: What similarities and differences are there between the development of H's speech and the development of speech in normally developing children? The answers can be stated as follows:

- H's consonant inventories were considerably more restricted than normally developing children of the same age, and showed very little development over the $21 / 2$ years during which the study was conducted;

- However, $\mathrm{H}$ had problems with the same groups of sounds as normally developing children: fricatives, $/ \mathrm{r} /$, labial sounds in final position and phonation

- At all three stages H's vowels appeared to cluster in a few areas in the vowel quadrilateral

- Finally, Hs systems of contrastive phones showed two interesting features:

- Her word initial system developed towards a state consistent with the phonotactics rules of the target language

○ The word final system grew from consisting of two phones (each occuring once in the material) to a system comparable to the initial and medial systems in size. This course of development is similar to that of normally developing children.

- Hypotonia was seen as a likely cause for the restricted inventories

In sum, H's phonological development is both similar and different from normally developing children. When similar, it is clearly delayed. When different, some of the differences may be attributed to her lack of muscular control. 


\section{Acknowledgement}

I am grateful to my colleagues Hanne Gram Simonsen and Inger Moen for their useful comments on an earlier draft of this paper.

\section{References}

Cornish, K., Bramble, D., MuniR, F. and Pigram, J., 1999, Cognitive functioning in children with typical cri du chat (5p-) syndrome. Developmental Medicine and Child Neurology, 42, 263-266.

Cornish, K., Cross, G., Green, A., Willatt, L. and Bradshaw, J.M., 1999, A neuropsychological-genetic profile of atypical cri du chat syndrome: implications for prognosis. Journal of Medical Genetics, 36, 567-570.

CORNISH, K. and MUNIR, F., 199,. Receptive and expressive language skills in children with cri du chat syndrome. Journal of communication disorders, 31, 73-81.

CORNISH, K. and PIGRAM, J., 1996, Developmental and behavioural characteristics of cri du chat syndrome. Archives of disease in childhood, 75, 448-450.

KRISTOFFERSEN, G., 2000, The phonology of Norwegian (Oxford: Oxford University Press).

KENT R.D, and MOLL, K.L., 1969, Vocal-tract characteristics of the stop cognates. Journal of the Acoustical Society of America, 46,1549 - 1555.

Moen, I., Simonsen, H.G., Huseby, M., and Grue, J., 2001, The relationship between intraoral air pressure and tongue/palate contact during the articulation of Norwegian /t/ and /d/, In: P. Dalsgaard, B. Lindberg and H. Benner (Eds): Proceedings, Eurospeech 2001 Scandinavia. Aalborg, Denmark: 265-268

ROTHENBERG M., 1968, The breath-stream dynamics of simple-released-plosive production. Phonetica, 6, $202-212$.

SIMONSEN, H. G., 1990, Barns fonologi: system og variasjon hos tre norske og ett samoisk barn (Unpublished doctoral thesis, University of Oslo, Norway).

SIMONSEN, H. G., 1997, Norske barns fonologi: universelle trekk og individuell variasjon. In: R. Söderbergh (Ed): Från joller til läsning och skrivning (Malmö: Gleerups), pp. 33 46. 